\title{
A review of imaging modalities for detecting early keratoconus
}

\author{
Xuemin Zhang ${ }^{1} \cdot$ Saleha Z. Munir $\mathbb{D}^{1} \cdot$ Syed A. Sami Karim ${ }^{1} \cdot$ Wuqaas M. Munir $\mathbb{D}^{1}$
}

Received: 13 April 2020 / Revised: 28 May 2020 / Accepted: 10 June 2020 / Published online: 16 July 2020

(c) The Author(s), under exclusive licence to The Royal College of Ophthalmologists 2020

\begin{abstract}
Objectives Early identification of keratoconus is imperative for preventing iatrogenic corneal ectasia and allowing for early corneal collagen cross-linking treatments to potentially halt progression and decrease transplant burden. However, early diagnosis of keratoconus is currently a diagnostic challenge as there is no uniform screening criteria. We performed a review of the current literature to assess imaging modalities that can be used to help identify subclinical keratoconus.

Methods A Pubmed database search was conducted. We included primary and empirical studies for evaluating different modalities of screening for subclinical keratoconus.

Results A combination of multiple imaging tools, including corneal topography, tomography, Scheimpflug imaging, anterior segment optical coherence tomography, and in vivo confocal microscopy will allow for enhanced determination of subclinical keratoconus. In patients who are diagnostically borderline using a single screening criteria, use of additional imaging techniques can assist in diagnosis. Modalities that show promise but need further research include polarization-sensitive optical coherence tomography, Brillouin microscopy, and atomic force microscopy.

Conclusions Recognition of early keratoconus can reduce risk of post-refractive ectasia and reduce transplantation burden. Though there are no current uniform screening criterion, multiple imaging modalities have shown promise in assisting with the early detection of keratoconus.
\end{abstract}

\section{Introduction}

Keratoconus is a noninflammatory, asymmetric corneal disorder characterized by progressive corneal thinning and protrusion, with resulting compromise in quality of vision [1]. Keratoconus was first described by Dr. Benedict Duddell in 1736, and later more precisely explained in written descriptions by Dr. John Nottingham in 1854 [1]. Keratoconus can be associated with Down syndrome, connective tissue disorders, Leber's congenital amaurosis, atopy, persistent eye rubbing, and hard contact lens wear [2, 3]. Clinical manifestations, such as Vogt striae, Fleischer's ring, conical corneal protrusion, and topographic changes, occur in later stages of the disease [2].

Keratoconus is a bilateral condition, but it may take years before the fellow eye of a patient with keratoconus manifests any clinical signs. "Forme fruste keratoconus" or subclinical

Wuqaas M. Munir

wmunir@som.umaryland.edu

1 Department of Ophthalmology and Visual Sciences, University of Maryland School of Medicine, Baltimore, MD, USA keratoconus can be used to describe eyes in which there are only mild topographic changes, but no clinical findings, with manifest keratoconus in the fellow eye. Keratoconus suspect is used to describe patients with eyes suspicious for keratoconus on topography without clinical findings, but the fellow eye does not have keratoconus [1].

Accurate screening for keratoconus suspects is imperative when evaluating refractive surgery candidates given the risk for iatrogenic corneal ectasia [4]. Furthermore, early identification of keratoconus patients allows for early corneal collagen cross-linking treatments, which protects against further corneal deformation and has already been shown to reduce transplantation burden [5].

Unfortunately, the detection of early keratoconus is currently a diagnostic challenge as there are often no presenting clinical signs and no uniform screening criteria available [6]. Neither of the current keratoconus classification or staging systems, including the Keratoconus Severity Score from the Collaborative Longitudinal Evaluation of Keratoconus (CLEK) study nor the Amsler-Krumeich classification, provide guidelines for the detection of early keratoconus [7].

Gomes et al. used the Delphi method to attempt to generate a consensus with regards to definitions, diagnosis, 
and management of keratoconus [3]. The panel mentioned abnormal posterior corneal ectasia, epithelial thickness distribution, and clinical noninflammatory thinning as findings to diagnose keratoconus. They also mentioned steepening of the anterior surface, posterior surface, and the rate of corneal thinning as potential factors to monitor for documenting progression [3]. However, the Delphi panel spurred much debate as to the validity of using current posterior corneal measurement modalities [8, 9]. As such, there is currently no accepted universal guideline to address diagnosis nor to document progression in keratoconus.

Given the importance of identifying forme fruste keratoconus and keratoconus suspects due to the lack of uniform criteria, this review will discuss current imaging modalities and advancements on the horizon that can be used to help detect early keratoconus.

\section{Methods}

A Pubmed database search was conducted. A total of 599 articles published from 1971 to 2019 were found in relation with keratoconus imaging, subclinical keratoconus, and forme fruste keratoconus. Of these, 100 articles were included in this analysis. We included primary and empirical studies. Exclusion criteria included case reports, non-English studies, and articles unrelated to the primary subject of this review.

\section{Results}

\section{Keratometry}

The first keratometer, originally known as an ophthalmometer, was invented by Hermann Von Helmholtz in 1855 [10]. This was the first instrument described to measure the corneal radius in a living human eye. Later, a modified version of this device was introduced to the ophthalmic community by Javal and Schiotz, which made it easier to clinically measure corneal astigmatism and its axis [10]. The keratometer uses subjectively aligned mires to find minimum keratometry $(K)$ and maximum $K$ readings and their axes using four points that are focused on the 3.0-4.0 mm central corneal zone.

Distorted mires, steep corneas, and high astigmatism using a manual keratometer (Javal Schiotz or Bausch and Lomb) or automated keratometry may signify keratoconus. Although a keratometer is an inexpensive and easy to use tool in detecting corneal astigmatism, the measurements are limited to the central corneal curvature. Further, though it is accurate for regular spherocylindrical surfaces, it is not reliable when assessing irregular corneas. Qualitative visualization of the mires through manual keratometry is an excellent way to diagnose keratoconus, but it is more time intensive, decreasingly available, and less familiar to most providers who now rely on advancing qualitative technologies. When assessing repeatability of multiple devices, Hashemi et al. found that manual keratometry had comparable repeatability to other more advanced imaging modalities, though this is dependent on user experience. Similar to other devices, when the maximum $K$ was $>55.0 \mathrm{D}$, the manual keratometer had reduced measurement reliability [11]. More advanced technologies now rely on more quantitative data, which for better or for worse rely less on user experience.

\section{Photo/video keratoscopy}

Corneal topography refers to anterior corneal surface imaging. The most commonly used technology is Placido discbased imaging, a noninvasive technique to analyse the anterior corneal surface quantitatively and qualitatively. It is currently the gold standard imaging modality in evaluating corneal ectasia [12]. The Placido disc is the oldest and most widely used topography method derived from the development of the Goode keratoscope by Antonio Placido da Costa in 1880 [13]. This device reflected concentric black and white rings off of the patient's tear film, allowing analysis of the spaces between them to assess corneal curvature data. Similarly, hand-held keratoscopes are currently used at the slit lamp for a rapid qualitative assessment of topography using the reflection of seven concentric rings. The resulting mires are used to infer information, such as mires that are closer together represent steeper corneal curvature, whereas, widely spaced mires represent flatter curvature [13].

Current Placido disc-based corneal topographers, or photo/video keratoscopes, are devices that use photographs of Placido disc reflections off the anterior corneal surface and provide quantitative information by generating curvature maps using computational technology. The axial or sagittal curvature map measures the corneal curvature from the optical axis and assumes the corneal surface to be spherical, thus providing both a qualitative assessment through the use of differing colors and a global assessment of corneal curvature (Fig. 1). The tangential (or instantaneous) map measures the corneal surface based on the local curvature radii and more accurately reflects the peripheral cornea, thus providing higher data sensitivity [13].

Placido disc-based corneal topography can generate indices that quantify the amount of corneal surface irregularities [14-22]. Several indices have been evaluated and found to be sensitive in detecting keratoconus (Table 1a, b). Maeda et al. used the average of simulated keratometry ( SimK) values $>45.7$ to be $84 \%$ sensitive for clinical keratoconus, but misclassified $40 \%$ of the maps with mild 
keratoconus [16]. Though not specific, corneal wavefront aberrations such as vertical and total coma, corneal total higher-order aberrations, and higher-order astigmatism have also been shown to be significantly higher in subclinical keratoconus as compared with keratoconus [17].

Several multivariate keratoconus systems have also been evaluated with varying sensitivities and specificities (Table 2). The modified Rabinowitz-McDonnell test, characterized by $K$ value $>47.2 \mathrm{D}$ and/or inferior-superior (I-S)

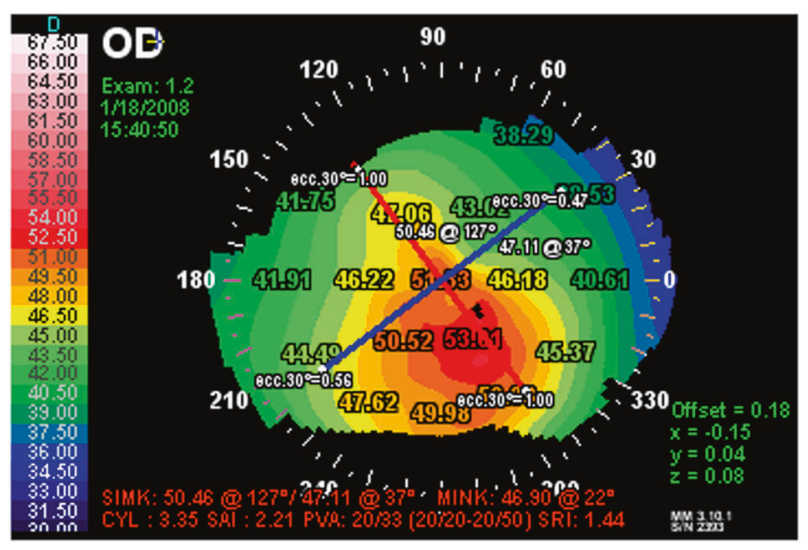

Fig. 1 Axial curvature map of a patient with keratoconus. Topography of a patient with a pattern diagnosis revealing a classic asymmetric bowtie pattern with skewed radial axis consistent with keratoconus. value of $>1.4 \mathrm{D}$, has been described in detecting keratoconus [23]. The modified Rabinowitz-McDonnell test has been found to be $96 \%$ sensitive and $85 \%$ specific in detecting keratoconus [16]. Maeda et al. developed the keratoconus prediction index (KPI), which is calculated through a discriminant analysis of eight topographic indices, including SimK1 (SimK value for the major axis), SimK2 (SimK value for the minor axis), surface asymmetry index, differential sector index, opposite sector index, center/surround index, and analysed area [19]. A KPI value of $>0.23$ is thought to be suggestive of keratoconus and was found to have a sensitivity of $89 \%$ and specificity of $99 \%$ for detecting keratoconus [19]. Neither of these tests were designed to identify keratoconus suspects. The keratoconus percentage index (KISA\%) is an index derived from multiplying the $K$ value, I-S value, keratometric astigmatism index (AST), and relative skewing of the steepest radial axes $[20,22]$. A KISA\% index of $>100 \%$ was noted to be sensitive and specific for diagnosis of keratoconus. Rabinowitz further suggested that a KISA\% index of $60-100 \%$ can be used to diagnose suspects [22]. Smolek and Klyce trained a neural network using ten different topographic indices as network inputs to detect keratoconus suspects, with the keratoconus severity index (KSI) [18, 24]. A KSI value of $<15 \%$ is considered normal, whereas, values between 15 and $30 \%$ are considered as keratoconus suspects, and values $>30 \%$ are subclinical keratoconus [18].

Table 1a Individual topographic indices in keratoconus.

\begin{tabular}{|c|c|c|c|}
\hline Individual indices & Description & $\begin{array}{l}\text { Probable } \\
\text { keratoconus }\end{array}$ & Clinical keratoconus \\
\hline $\begin{array}{l}\text { Central keratometry } \\
\text { (K central) }\end{array}$ & Average corneal power for ring diameters of 2,3 , and $4 \mathrm{~mm}$ & $47.2-48.7$ & $>48.7[18]$ \\
\hline $\begin{array}{l}\text { Inferior-superior } \\
\text { value (I-S) }\end{array}$ & $\begin{array}{l}\text { Power difference between } 5 \text { points of the superior and inferior } \\
\text { hemisphere at } 3 \mathrm{~mm} \text { from the corneal apex with spatial intervals of } \\
30^{\circ} \text {. A positive value indicates a higher inferior curvature and a } \\
\text { negative value indicates a higher superior curvature }\end{array}$ & $1.4-1.8$ & $>1.8[19]$ \\
\hline $\begin{array}{l}\text { Skew of steepest } \\
\text { radial axis (SRAX) }\end{array}$ & $\begin{array}{l}\text { Angle between superior semi-meridian and inferior semi-meridians, } \\
\text { determined by averaging powers of rings from } 5 \text { to } 16 \mathrm{~mm}\end{array}$ & & $>21^{\circ}[20]$ \\
\hline Apex curvature $(\mathrm{AK})$ & Instantaneous curvature in the corneal apex & $48-50 \mathrm{D}$ & $>50 \mathrm{D}[20]$ \\
\hline $\begin{array}{l}\text { Asphericity } \\
\text { coefficient }(\mathrm{Q})\end{array}$ & $\begin{array}{l}\text { Index describing corneal curvature change from central region to the } \\
\text { peripheral region. A normal cornea has a average } Q \text { value of }-0.2 \pm \\
0.12(77) \text { and represents that the cornea is more curved in the center. } \\
\text { The value depends on the diameter of the study, which is usually set } \\
\text { at } 4-5 \mathrm{~mm}\end{array}$ & & $\begin{array}{l}\text { 1. }-0.84 \text { for anterior surface and } \\
-1.10 \text { for the posterior surface at } \\
8 \mathrm{~mm}[14] \\
\text { 2. }-0.65 \text { to }-1.18 \text { for the anterior } \\
\text { surface and }-1.17 \text { to }-0.6 \text { for the } \\
\text { posterior surface [15] }\end{array}$ \\
\hline $\begin{array}{l}\text { Corneal irregularity } \\
\text { measurement (CIM) }\end{array}$ & $\begin{array}{l}\text { Degree of corneal surface irregularity by quantifying standard } \\
\text { deviation between corneal surface and best-fit reference }\end{array}$ & $0.69-1 \mu \mathrm{m}$ & $1.10-5.00 \mu \mathrm{m}[21]$ \\
\hline $\begin{array}{l}\text { Calossi-Foggi Apex } \\
\text { curvature } \\
\text { gradient (ACG) }\end{array}$ & $\begin{array}{l}\text { Average difference per length unit of the corneal power relative to } \\
\text { the apical power }\end{array}$ & $1.5-2.0 \mathrm{D}$ & $>2.0 \mathrm{D}[21]$ \\
\hline $\begin{array}{l}\text { Calossi-Foggi } \\
\text { Top-Bottom Index }\end{array}$ & $\begin{array}{l}\text { Vertical asymmetric index indicating difference in average power } \\
\text { between superior and inferior area. A positive value indicates an } \\
\text { inferior area that is more curved }\end{array}$ & $1.5-2.0 \mathrm{D}$ & $>2.0 \mathrm{D}[21]$ \\
\hline
\end{tabular}


Table 1b More individual topographic indices in keratoconus that are incorporated into multivariate topographic indices.

Individual Indices Description

Simulated keratometry (SIMK)

Surface asymmetry index (SAI)

Differential sector index (DSI)

Opposite sector index (OSI)

Center/surround index (CSI)

Analysed area (AA)
Diopter power of flattest and most curved meridians in the ring diameters between 3 and $9 \mathrm{~mm}$. The difference between K1 and K2 is the AST index, or quantitative value for corneal astigmatism [22]

Average power difference between points located $180^{\circ}$ from 128 equidistant meridians. There is an increase in power difference as the cornea is more asymmetric [21]

Average power difference $45^{\circ}$ sectors with the highest and lowest power [21]

Average power difference between opposite $45^{\circ}$ sectors [21]

Average power difference between the central $3 \mathrm{~mm}$ zone and half peripheral 3 and $6 \mathrm{~mm}$ rings [21] Ratio of data area that is peripherally circumscribed [21]

Table 2 Multivariate topographic indices in keratoconus.

\begin{tabular}{|c|c|c|c|}
\hline Multivariate indices & Description & Probable keratoconus & Clinical keratoconus \\
\hline KISA\% index & $(\mathrm{K}) \times(\mathrm{I}-\mathrm{S}) \times(\mathrm{AST}) \times(\mathrm{SRAX})$ & $60-100 \%$ & $>100 \%[22]$ \\
\hline $\begin{array}{l}\text { Keratoconus } \\
\text { severity index KSI) }\end{array}$ & Neural network using ten different topographic indices & $15-30 \%$ & $>30 \%[18]$ \\
\hline $\begin{array}{l}\text { Keratoconus prediction } \\
\text { index (KPI) }\end{array}$ & $\begin{array}{l}\text { Uses a combination of indices: SimK1, K2 Sim, UPS, } \\
\text { DSI, OSI, CSI, IAI and AA, and a linear discriminant } \\
\text { function }\end{array}$ & $\begin{array}{l}\text { Not designed for detecting } \\
\text { suspects }\end{array}$ & $>0.23[19]$ \\
\hline $\begin{array}{l}\text { Modified Rabinowitz/ } \\
\text { McDonnell index }\end{array}$ & Calculated from $\mathrm{K}$ central and $\mathrm{I}-\mathrm{S}$ values & $\begin{array}{l}\text { Not designed for detecting } \\
\text { suspects }\end{array}$ & $\begin{array}{l}\text { Maps with central corneal } \\
\text { power }>47.2 \mathrm{D} \text { and/or an } \\
\mathrm{I}-\mathrm{S} \text { value }>1.4 \mathrm{D}[23]\end{array}$ \\
\hline
\end{tabular}

Of note, the use of Placido-based corneal topography generates both intrinsic errors derived from the device itself and extrinsic errors derived from unmeasured patient factors, such as inadequate eyelid opening, poor patient focus, and poor tear film quality. Since Placido-based systems rely on curvature maps, they do not represent true elevation. This can lead to false assumptions about the simulated elevation of the cornea [13]. Corneal irregularity may lead to inaccurate topographic maps, thus making it difficult to differentiate keratoconus from contact lens-induced warpage [25], poor tear film quality, or lid artefact using topography alone [19]. More importantly, there is concern that topography does not detect all patients with subclinical keratoconus or those at risk for post-refractive ectasia. Randleman et al. reported that the preoperative topography was normal in $27 \%$ of 93 patients who developed post-refractive surgery corneal ectasia [9].

\section{Corneal tomography (visible light-based)}

\section{Dynamic skiascopy}

The NIDEK OPD-scan wavefront analyzer (NIDEK Co Ltd, Gamagori, Japan) provides an axial curvature map, keratometry data, and a Placido disc image (Fig. 2). It combines placido-disc-based corneal topography with a ray tracing aberrometer, based on the principle of dynamic retinoscopy, to provide information on the anterior cornea along with refractive error, keratometry, and the patient's quality of vision [13]. The OPD scan also provides optical path difference (OPD) maps which detects total refractive error in the eye as well as the refractive error contributed by the internal structures of the eye [26]. The NIDEK OPD scan has been used to evaluate the quality of vision in patients with keratoconus after corneal transplants [27], after intracorneal ring segment implantation [28], and after accelerated corneal cross-linking [29]. Asgari et al. evaluated mild and moderate keratoconus eyes after accelerated cross-linking and found that the OPD scan III had higher aberrometric repeatability in mild compared with moderate cases [30]. Further studies are needed to use NIDEK OPD scan in patients with forme fruste keratoconus.

\section{Slit-scanning topography}

The Orbscan (Bausch and Lomb, Rochester, NY, USA) uses slit-scanning technology to provided anterior and posterior elevation, keratometry maps, and wide-field pachymetry. Orbscan II is a later version that also added Placido-based topography analysis [1]. The Orbscan system has been found to provide useful information in detecting subtle changes in early keratoconus [31]. The Orbscan system incorporates anterior corneal curvature indices, pachymetry, and assessment of focal elevations and depressions from computergenerated best-fit sphere [32]. An I-S value of greater than 


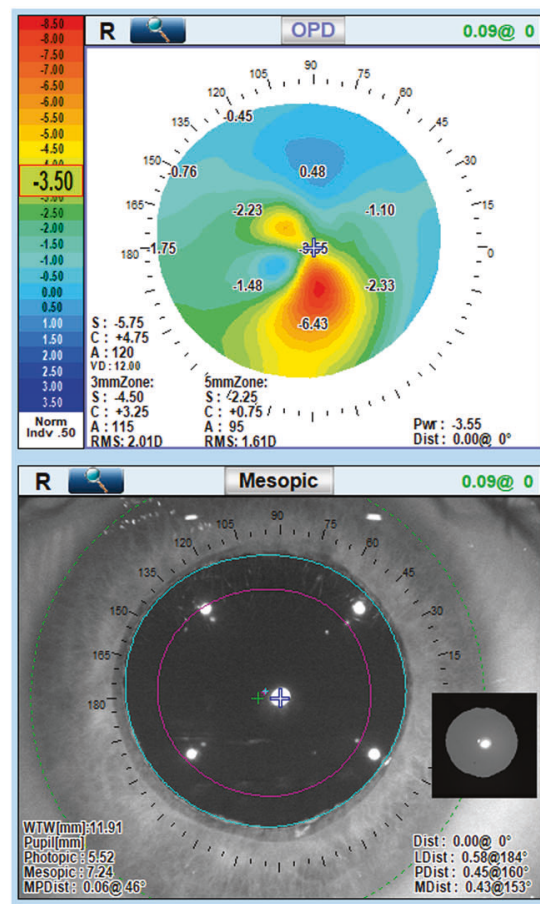

R A A 1 Axial $0.07 @ 207$

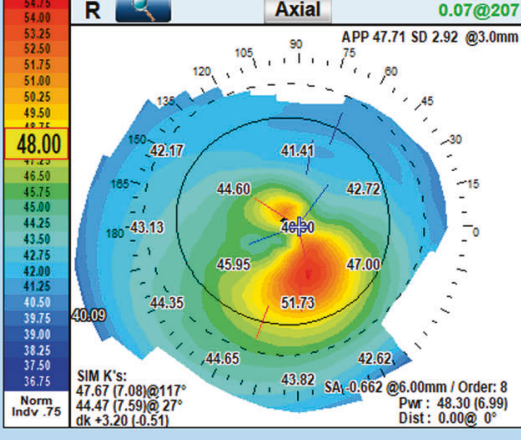

HOA [ $\mu \mathrm{m}]$ : Cornea@6.00mm

Total, Internal@6.00mm / Order = 3

T.Sph T.Coma T.Tre HO

Total: $\begin{array}{llll}0.000 & 0.939 & 1.920 & 2.137\end{array}$

Cornea: $0.000 \quad 2.028 \quad 1.447 \quad 2.491$

Internal: $0.000 \quad 1.089 \quad 0.500 \quad 1.198$

Refraction: VD $=12.00 \mathrm{~mm}$

\begin{tabular}{lcccc}
\hline & Sph & Cyl & Axis & RMS \\
REF & $\mathbf{- 5 . 7 5}$ & $\mathbf{+ 4 . 7 5}$ & $\mathbf{1 2 0}$ & \\
WF@6.00 & -3.75 & +2.75 & 115 & $2.33 \mathrm{D}$ \\
\multicolumn{1}{c}{ Diff } & +2.00 & -2.00 & -5 &
\end{tabular}

$\mathbf{R}$
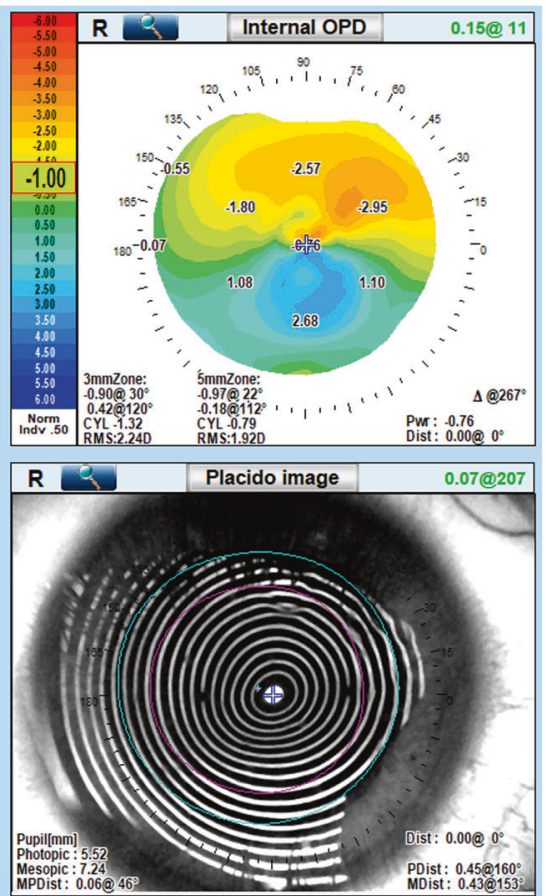

Fig. 2 NIDEK OPD III topography scan of a patient with keratoconus. The optical path difference (OPD) map, a representation of total refractive error of the eye, reveals inferior steepening (top left image). The axial curvature map is a placido-derived interpolation of the anterior corneal surface, displaying inferior steepening consistent with keratoconus (top middle image). The internal OPD map, which displays only the refractive error contributed by internal structures of the eye, suggesting an internal ocular contribution to the appearance of the OPD map (top right image). The mesopic map displays the corneal light reflex in comparison to angle alpha and angle kappa, the difference of which can be elevated in keratoconus (bottom left image). Higher-order astigmatism and increased corneal wavefront aberrations are also noted in keratoconus (bottom middle image). The Placido disc reveals concentric mires with noted steepening and irregularity inferiorly consistent with keratoconus (bottom right image).

Elevation maps are derived from comparing the reconstruction of the anterior and posterior surface to a best fitted surface, such as a sphere, toroid, revolution ellipsoid or nonrevolution ellipsoid with a typical reference of $8 \mathrm{~mm}$, thus providing anterior and posterior elevation of corneal apex, as well as elevation of the minimum thickness point. The pachymetric map is also reconstructed based on the anterior and posterior corneal surfaces [21].

The Pentacam measures both the anterior and posterior surface elevation and fits a best-possible sphere, toric ellipsoid, or ellipse to both surfaces. Apical protrusion can steepen the best-fit surface, thus decreasing the difference between the best-fit surface and cone apex. The Belin/ Ambrossio Enhanced Ectasia Display of the Scheimpflug system circumvents this problem by generating an enhanced best-fit sphere that excludes a $3.0-4.00 \mathrm{~m}$ area of thinnest pachymetry when calculating the reference image [35]. The "Belin ABCD" keratoconus grading system has also been incorporated in the OCULUS Pentacam software version 6.08 r16 [36]. It uses the anterior ("A") and posterior ("B" for back surface) radius of curvature taken from a $3 \mathrm{~mm}$ zone over the thinnest corneal area and corneal thickness ("C") at the thinnest point, as well as distance best corrected visual
The Pentacam Scheimpflug system (Oculus, Wetzlar, Germany) has a $180^{\circ}$ rotating Scheimpflug camera, which allows creation of a pachymetric map, characterization of the anterior chamber angle, and measurement of both the anterior and posterior surfaces of the cornea [1] (Fig. 3). 


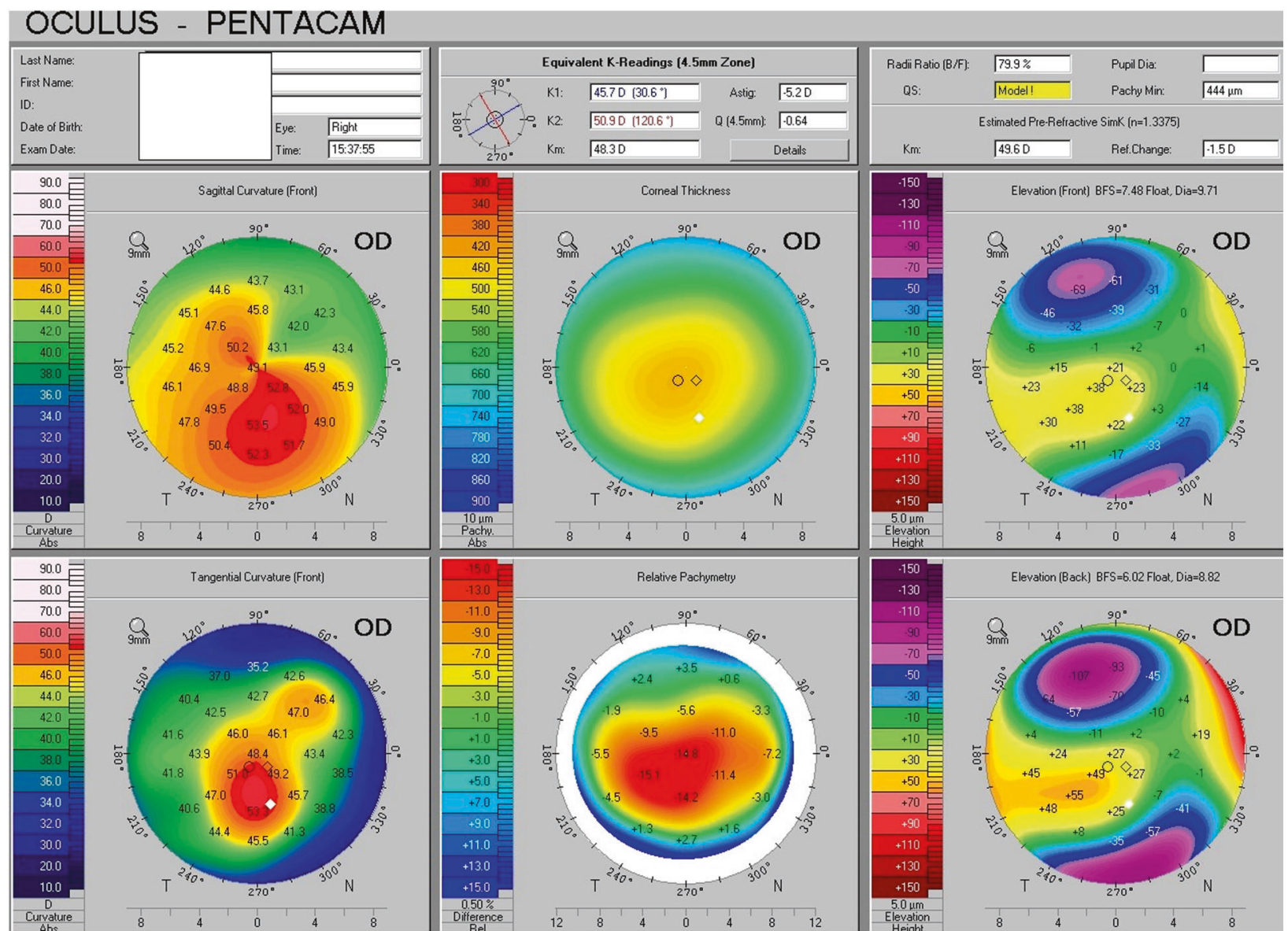

Fig. 3 Oculus Pentacam report of a patient with keratoconus. Axial power and tangential maps are displayed in the left column, pachymetry and relative pachymetry map in the middle, and elevation

acuity ("D") to assess keratoconus stage, and is graded from stages 0 to 4 [37]. The $3.0 \mathrm{~mm}$ zone corresponds to the Belin/Ambrosio Enhanced Ectasia Display exclusion zone, and contains the most ectatic area on the cornea [38]. It also adds a modifier of "-" for no scarring, "+" for scarring that does not obstruct iris details, and " ++ " for scarring that does obstruct iris details. The anterior corneal curvature in stages 1-4 have been found to correlate with the AmslerKrumeich classification. It allows for the posterior corneal surface to be assessed, unlike the traditional AmslerKrumeich classification system or the CLEK classification system [36]. The Belin ABCD keratoconus grading system grades the anterior and posterior corneal surfaces and thus may better depict further structural and functional changes in the cornea, however further research is needed to define parameters to assess subclinical keratoconus. Sedaghat et al. found that there was significant change in the anterior and posterior radii of curvature of the $3.0 \mathrm{~mm}$ zone, as well as significant improvement in corrected distance visual acuity, but no change in corneal thickness, after Keraring implantation in keratoconus patients [39]. of the anterior and posterior cornea relative to reference surfaces in the right column, with similar inferocentral "hot spot" regions across various maps indicative of keratoconus.

In comparing subclinical keratoconus eyes to eyes with myopic astigmatism, Cui et al. found that the difference between central corneal thickness and minimum corneal thickness of more than $5.5 \mu \mathrm{m}$ seemed to have the best predictive accuracy for subclinical keratoconus [40]. Corneal densitometry, or corneal backscatter, which has been implicated in ocular surface disease, has been shown to be elevated in the anterior layer and correlated with severity of corneal keratometry in keratoconus [41]. De Sanctis et al. found that posterior corneal elevation of greater than $29 \mu \mathrm{m}$ could be used as a relatively specific (90.8\%), but nonsensitive $(68 \%)$ measure of detecting subclinical keratoconus [42]. They suggested that though posterior corneal elevation derived from the Pentacam cannot be used alone to diagnose subclinical keratoconus, that it can be adjunct to other factors [42]. Similarly Mihaltz et al. found that posterior elevation, with a cutoff value of $15.5 \mu \mathrm{m}$, was the most effective parameter to use in diagnosing keratoconus with $95.1 \%$ sensitivity and $94.3 \%$ specificity [43]. Muftuoglu et al. found that back difference elevation, or relative change in elevation from baseline elevation in a $4.0 \mathrm{~mm}$ 
exclusion zone over the thinnest point of the cornea, with a cutoff of $13.2 \mu \mathrm{m}$ was able to detect forme fruste keratoconus with higher sensitivity (74\%) and specificity (65\%) than posterior elevation [44].

The Pentacam HR is a newer model that uses a highresolution rotating Scheimpflug camera to further capture images of the anterior segment and obtain total corneal refractive power and distribution, anterior chamber angle and depth measurements, corneal and crystalline lens optical opacities [45]. The Pentacam AXL is the newest model which also integrates an axial length measurement [46].

The Sirius Corneal tomographer (Costruzione Strumenti Oftalmici, Firenze, Italy) has a single Scheimpflug rotating camera and Placido disc, but it only has a single 25 scan setting with 1 Placido image, as compared with the Pentacam which has 25 or 50 three-dimensional scans [47]. It is also able to derive anterior and posterior cornea, anterior lens, and iris profiles from the Scheimpflug images. Zhang et al. retrospectively analysed 1632 eyes using the Sirius imaging system, specifically evaluating the corneal anterior surface, posterior surface, and minimum thickness data in suspects and found statistically significant differences for those values in patients with subclinical keratoconus as compared with normal [47]. Arbelaez et al. applied a support vector machine, a machine learning classifier, to the corneal measurements provided by Sirius and were able to accurately classify eyes as normal, keratoconus, subclinical keratoconus, or abnormal [48]. They found posterior corneal curvature and pachymetric data to be important in the detection of subclinical keratoconus [48].

\section{Dual Scheimpflug imaging}

The Galilei camera (Ziemer Ophthalmic Systems AG, Port, Switzerland) is a relatively new device that is similar to the Pentacam in that it combines Placido disc-based corneal topography with elevation data from Scheimpflug technology, but has simultaneously recording dual rotating Scheimpflug cameras spaced $180^{\circ}$ apart [49]. This has the benefit of tracking eye movements and decentration, thus reducing motion error especially with scans at oblique angles [50].

The indices that have been deemed diagnostically significant in assessing for forme fruste keratoconus include an irregular astigmatism index of $>0.450$, a standard deviation of corneal power $>1.065$, and a surface regularity index of $>0.735$ [50]. Feizi et al. analysed parameters measured using Galilei in 23 subclinical eyes when compared with normal and eyes with keratconus, and found that though surface indices and elevation data had a $100 \%$ predictive ability to distinguish keratoconus, none of the variables could independently detect subclinical keratoconus. They suggest that a 3-factor model with keratometric values, elevation data, and surface indices had the highest predictive value for detecting subclinical keratoconus [51]. Jafarinasab et al. evaluated the maximum anterior and posterior corneal elevation in the central 3.0, 5.0, and $7.0 \mathrm{~mm}$ zones using the Galilei camera. They found that the posterior elevation in the $3.0 \mathrm{~mm}$ zone best distinguished keratoconus from normal, but that the $7.0 \mathrm{~mm}$ zone with optimal cutoff for posterior elevation of $50.5 \mu \mathrm{m}$ best distinguished subclinical keratoconus eyes with $79.9 \%$ sensitivity and $94 \%$ specificity [52].

Shetty et al. assessed the repeatability of several parameters using Pentacam, Galilei, and Sirius in 55 eyes of 55 patients with keratoconus. They found that the devices showed repeatability in mean keratometry, thinnest corneal thickness, anterior chamber depth, and mean posterior keratometry. However, it was noted that there were significant differences between the devices and thus cannot be used interchangeably for anterior segment imaging [53]. Similarly, in the assessment of repeatability using the Orbscan II, the Galilei, and the Pentacam HR by Meyer et al. keratometric and pachymetric measurements were disparate in keratoconus eyes, especially with the Orbscan. The Pentacam HR had the highest repeatability for keratometry measurements and the Galilei showed highest repeatability for pachymetry meaurements [54].

\section{Anterior segment optical coherence tomography}

While visible light-based tomography systems are very widely used and incorporate both anterior and posterior corneal indices and corneal thickness measurements to aid with the assessment [3], they are sensitive to poor ocular surface, have relatively long image acquisition time, and are unable to provide corneal anatomic detail [55]. Optical coherence tomography (OCT) may be able to overcome these limitations with higher resolution images and faster acquisition times, thus limiting motion artifact [56].

OCT is an imaging technique based on low-coherence interferometry using near-infrared light and is able to provide high-resolution information on tissue morphology, including thickness maps of the individual corneal layers [56] (Fig. 4). Spectral domain and swept-source OCT devices allow anterior and posterior topography, in addition to cross-sectional corneal imaging, with faster acquisition time while maintaining detail [57].

\section{Time-domain optical coherence tomography (TD-OCT)}

The Visante-OCT system (Carl Zeiss Meditec Inc, Dublin, CA, USA) has a scan speed of 2048 A-scans/s with eight radial scans that are centered on the cornea [58], and is 


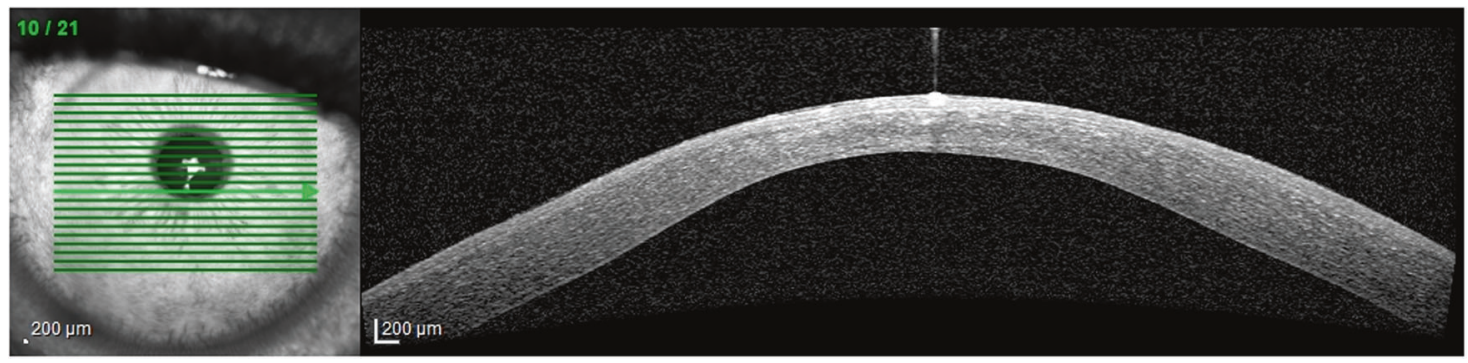

Fig. 4 Optical coherence tomography in a patient with keratoconus. Focal corneal thinning is noted in this anterior segment optical coherence tomography which is consistent with keratoconus.

currently the fastest available commercial TD-OCT system [59]. In this system, a combination of reflected light from the sample arm (i.e., the eye) and a reference arm (typically a mirror) gives rise to an interference pattern. When scanning the reference arm, a reflectivity profile or axial depth scan (A scan) is obtained. A cross-sectional tomography (B scan) can then be obtained by combining a series of A scans [59]. Li et al. [60] described an OCT pachymetry-based method using the Visante anterior segment OCT System (Carl Zeiss Meditec Inc.) to assess for focal corneal thinning in the central $5 \mathrm{~mm}$ zone, as well as asymmetric thinning in a $2-5 \mathrm{~mm}$ diameter zone in subclinical keratoconus. This was found to be comparable to a topography-based KISA\% method for the diagnosis of keratoconus [60]. Qin et al. used five pachymetric variables and found that this further improved to diagnostic power, with the best single pachymetric variable being the minimum corneal thickness [61]. However, the clinical utility of these metrics remains limited, as ascertaining these measures requires manual intervention given no analytical software is included on this platform. Further, the acquisition time of these systems is limited due to the required cycle time of the reference mirror.

\section{Spectral-domain OCT (SD-OCT)}

Instead of a reference arm moving as in time-domain OCT, a stationary mirror allows for higher speeds and thus improved resolution in SD-OCT. The sample and reference reflections produce interference that is detected as spectrum, and subsequent fourier transformation of the subsequent spectral interferogram produces the A scan [59]. Available instruments include RTVue-OCT (Model RT100, Optovue Inc, Fremont, CA, USA), 3D OCT-1000 (version 3.01, Mark II; Topcon Corporation, Tokyo, Japan), Cirrus OCT (version 3.0, Model 4000; Carl Zeiss Meditec, Inc., Dublin, CA), and Spectralis OCT (Heidelberg Engineering, Germany).

The RTVue-OCT with corneal module has a scan speed of 26,000 A-scans/s, with a scan beam wavelength of $8409 \mathrm{~nm}$, axial resolution of $5 \mu \mathrm{m}$, and transverse resolution of $8 \mu \mathrm{m}$. The low magnification cornea anterior module (CAM-L) is a lens adapter to allow for assessment of the cornea when used with the RTVue-OCT [59]. The RTVueOCT is one of the few instruments that includes analytical software that can generate keratoconus analysis tables using the thinnest corneal pachymetry. It was found to correlate with the time-domain OCT system, but generated higher thinnest corneal thickness readings for normal eyes compared with the time-domain OCT [58]. Li et al. found that with RTVue-OCT, corneas with subclinical keratoconus had significantly higher corneal epithelial, stromal, and pachymetric pattern standard deviation scores. They found the epithelial pattern standard deviation of $>0.041$ to be 96\% sensitive and $100 \%$ specific for detecting subclinical keratoconus. Li et al. also assessed corneas with Cirrus HDOCT, and determined five pachymetric diagnostic parameters to assess focal and asymmetric thinning in keratoconus based on an OCT pachymetric map focused on the central $5 \mathrm{~mm}$ zone [60].

\section{Swept-source optical coherence tomography (SS- OCT)}

Swept-source anterior segment optical coherence tomography (SS-OCT) devices use low-coherence interferometry using a long wavelength scanning-laser source and balanced photodetectors to analyse the anterior and posterior cornea $[62,63]$. Both SS-OCT and SD-OCT use Fourier domain detection, however SS-OCT instruments use a tunable swept laser with a wavelength of around $1050 \mathrm{~nm}$ and a single photodiode detector as compared with SD-OCT which uses a broadband near-infrared superluminescent diode as a light source with a wavelength of around $840 \mathrm{~nm}$. SS-OCT has an even faster scanning speed and uses a longer laser wavelength and higher laser power, which allows for improved signals detection of deeper layers [64].

Steinberg et al. found that when using SS-OCT (Casia SS1000; Tomey Corp, Inc, Nagoya, Japan) with a combination of automated and newly-calculated parameters, it is capable of a high specificity (93\%) but low sensitivity 
$(51 \%)$ in detecting subclinical keratoconus [62]. The Casia analysis program is able to calculate keratometric, anterior, posterior, pachymetric, and Fourier indices based on anterior and posterior corneal surface data. The automated parameters with highest accuracy for detecting subclinical keratoconus include Fourier indices based on higher-order irregular astigmatism and asymmetry. The newly generated variables were based on asymmetry between upper and lower corneal hemispheres, and based on changes that occur surrounding the thinnest corneal thickness or point of maximum keratometry progression [62]. They found that while posterior corneal elevation effectively distinguished keratoconus eyes from normal eyes, that it should not be used as a stand-alone parameter for diagnosing subclinical eyes [62]. Gutierrez-Bonet et al. found that choroidal vascularity, choroidal, stromal, and vascular areas were thicker in keratoconus patients using SS-OCT, though the reason behind the changes is not yet known [65].

SS-OCT has been noted to have good agreement with a Scheimpflug system on most values of the anterior and posterior corneal keratometry indices [66] and was found to have better repeatability of measuring corneal thickness and posterior corneal elevation [63]. Jhanji et al. found that SSOCT demonstrated better reproducibility coefficients and intraclass correlation coefficients as compared to slitscanning tomography [67].

\section{Epithelial mapping}

The corneal epithelium can change and rebuild itself in response to changes in the stroma and thus can prevent early diagnosis of keratoconus using topography. Thus, evaluating epithelial thickness can be a useful tool in assessing early stages of keratoconus. High-resolution OCT, very-high frequency digital ultrasound, or confocal imaging can all be used to evaluate this, however OCT benefits from being noncontact and an extremely low acquisition time thus reducing motion artefact. With epithelial mapping, Temstet et al. found that a thin epithelial thickness in the thinnest corneal zone with a cut-off point of $52 \mu \mathrm{m}$ differentiated forme fruste keratoconus from normal eyes with a $88.9 \%$ sensitivity and a $59.5 \%$ specificity [68]. Ostadian et al. found that patients with subclinical keratoconus had lower minimum epithelial thickness as well as compensatory thickening in the inferior and one eighth of the temporal aspect of the SD-OCT corneal epithelial map [69]. Li et al. found that keratoconus eyes had larger pattern and map standard deviation, more negative minimum-maximum, greater superior-inferior, and lower inferior and minimum corneal epithelial thickness values [70]. Similarly, Rocha et al. found apical epithelial thickness to be significantly thinner in keratoconus eyes, with increased variability [71].

\section{Polarization-sensitive optical coherence tomography (PS-OCT)}

PS-OCT measures birefringence of tissue and is used to study the microscopic structure of fibrous tissues [72]. It is able to provide information on distribution of birefringence, unlike conventional OCT. A superluminescent diode emits a vertically polarized low-coherence beam, which is then split into sample and reference beams [72]. After the beams rotated and processed through tissue, the beams combine and are then split again by a polarizing beam splitter to be recorded by photodetectors [72]. Corneal tissue is optically birefringent, with stroma composed of 200 lamellae of parallel collagen fibrils. The fibrils in different lamella are typically oriented orthogonally to each other, with birefringent properties that thus cancel each other out [73].

In keratoconus corneas, the typical parallel collagen fibril arrangement is disrupted and thus results in a change in birefringence [72, 74], resulting in a change in net retardation and optic axis orientation [72, 73, 75]. Fukuda et al. found that some cases of keratoconus suspects had increased birefringence and no alterations in posterior elevation, suggesting that collagen fiber changes may actually develop before posterior corneal elevation changes [76]. PS-OCT may be able to detect disruptions in fibril arrangement in subclinical keratoconus and could potentially be applied to clinical use in the future.

\section{In vivo confocal microscopy}

\section{Slit confocal microscopy}

While other imaging modalities assess corneal curvature and elevation, confocal microscopy assesses the corneal architecture at the cellular level. Ozgurhan et al. suggests that anterior and posterior stromal keratocyte density are lower in subclinical keratoconus, and even lower in keratoconus as compared with controls [77]. On the other hand, Weed et al. found that anterior and posterior stromal keratocyte density increased in moderate and advanced keratoconus [78]. Erie et al. suggests that there is no difference in keratocyte density between keratoconus patients and controls, but that keratoconus patients who were also contact lens wearers did have $10 \%$ lower keratocyte density [79].

Ucakhan et al. reports that elongated superficial epithelial cells, stromal folds, thickened subbasal nerves, and increased pleomorphism and polymegathism of endothelial cells are suggestive of keratoconus [80]. Ozgurhan et al. also suggests that mean subbasal nerve density and mean stromal nerve diameter are higher in patients with subclinical keratoconus as compared with normal eyes [77]. Given limited studies and conflicting findings, confocal 
microscopy currently remains of limited diagnostic value for subclinical keratoconus, but may eventually serve as a good adjunctive method for diagnosis.

\section{Noncontact tonometry}

It is thought that biomechanical alternations of the cornea are related to the onset of keratoconus $[74,81]$ and can also be useful in monitoring efficacy of cross-linking [5]. Other imaging modalities using videokeratography or OCT can detect alterations in shape of cornea, but they are unable to measure biomechanical structural changes in corneal morphology [82].

Two such examples of this technology are the Ocular Response Analyzer (ORA, Reichert, Inc., Depew, NY) and the CorVis ST (CST; Oculus, Wetzlar, Germany). The ORA uses a rapid air pulse to indent the cornea and uses an electro-optical system to record pressure measurements. The pressure when the cornea is indented is recorded and the pressure when the cornea moves back outward is recorded as well, thus allowing for dynamic bidirectional applanation [83]. Corneal hysteresis is the difference between these measurements and reflects corneal viscosity. Corneal resistance factor can also be calculated from these values and represents the overall resistance of the cornea [83]. Although outside the scope of this imaging review, Schweitzer et al. suggest that corneal hysteresis and corneal resistance factor provided by ORA can provide information in screening for subclinical keratoconus, but have been to be insufficient alone in identifying subclinical keratoconus [84-86].

The CorVis ST is another commercially available device that uses a single air puff to cause deformation of the cornea, and uses a Scheimpflug camera to record the response of the cornea $[87,88]$. The Corvis records $\mathrm{A}^{1 / 2}$ length, $\mathrm{A}^{1 / 2}$ velocity, highest concavity deformation amplitude, radius of curvature, peak distance, central corneal thickness, and intraocular pressure [89].

$\mathrm{Wu}$ et al. noted that two indices, the radius value of the central concave curvature at highest concavity and the central corneal thickness, were increased in subclinical keratoconus patients using the CorVis ST [90]. Vinciguerra et al. found that the Corvis Biomechanical Index (CBI), which encompasses multiple corneal deformation characteristics, to be $100 \%$ specific and $94.1 \%$ sensitivity with a cutoff value of 0.5 in correctly classifying keratoconus eyes from healthy eyes [88]. Another parameter, the tomographic and biomechanical index (TBI) with a cutoff value of 0.76 provided $100 \%$ sensitivity and $100 \%$ specificity for detecting clinical ectasia [42]. In a case series of 12 patients with normal topography and tomography, Vinciguerra et al. further demonstrated an early evidence of biomechanical abnormalities in subclinical keratoconus eyes using CBI [82]. In a comparison between corneal tomography, Pentacam HR, and Corvis ST, Kataria et al. demonstrated that the TBI with a 0.63 cutoff actually showed the highest diagnostic accuracy for detecting eyes with mild ectasia [91]. Though further studies are needed, biomechanical analysis may be able to complement other modalities in diagnosing subclinical keratoconus.

\section{Brillouin light-scattering microscopy}

Brillouin microscopy is a noninvasive way to assess corneal mechanical changes. Brillouin spectroscopy measures the interaction between laser light (photons) and thermally generated acoustic vibrations (phonons). Thermal motion of atoms in the cornea generates acoustic vibrations, which lead to scattering of light. The frequency of scattered light is different from incident light, and is referred to as a Brillouin frequency shift. In a cornea, the Brillouin frequency shift allows for measurement of the bulk elastic modulus of the cornea [92]. The Brillouin system is comprised of a light source or laser on the cornea, and a high-contrast analyser to measure the frequency shift of the scattered light.

In corneas with keratoconus, it has been proposed that the degeneration of the cornea occurs in a focal fashion, rather than a generalized weakening, which then causes a cycle of strain and subsequent thinning of the cornea [81]. Brillouin light-scattering microscopy seems to validate this point. In early stage keratoconus, Brillouin light-scattering microscopy showed that cone regions had lower Brillouin shifts as compared with outside-cone regions $[92,93]$. The Brillouin frequency shift increases with age at $\sim 4 \mathrm{MHz}$ per decade in normal corneas, whereas the central aspect of keratoconus corneas have a significantly smaller Brillouin frequency shift both in vivo and ex vivo [94]. Furthermore, the Brillouin frequency shift has been found to correlate with geometric keratoconus indices at the point of maximum posterior elevation [92]. Unfortunately, Seiler et al. all found that a single measurement of Brillouin frequency shift to not be sensitive nor specific enough to detect early keratoconus [94]. Webb et al. were able to use Brillouin microscopy to assess for any localized stiffening in the cornea, and found that there was no change after crosslinking [95].

\section{Atomic force microscopy (AFM)}

While this modality is not yet in clinical use, atomic force microscopy can be used to assess both topographic and biomechanical properties of tissue [96]. AFM uses a laser 


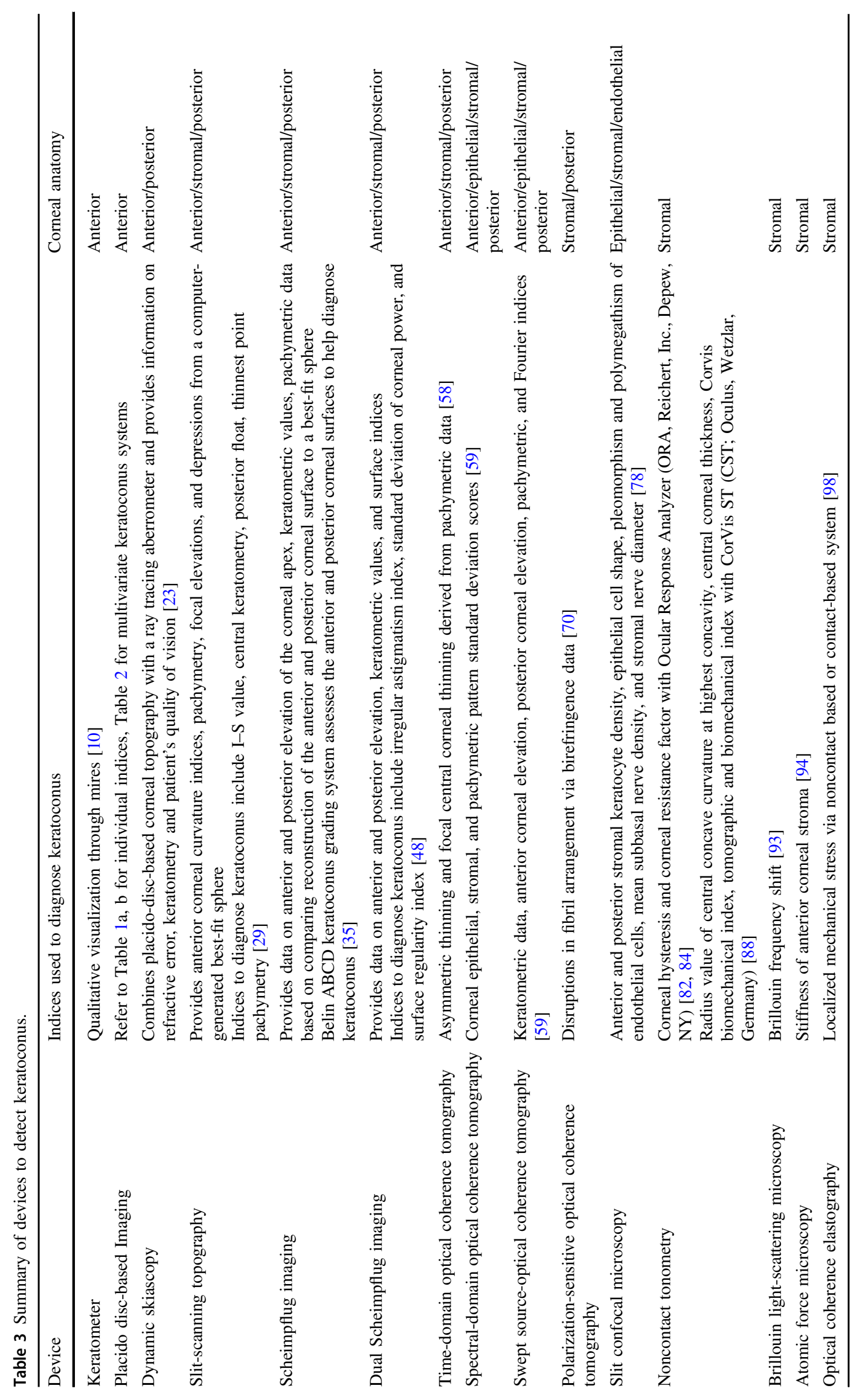


beam reflected from the back of the cantilever which is scanned across the eye and detected by a position-sensitive photodiode. In addition, the cantilever tip can also indent tissue to assess stiffness of tissue. Dias et al. used atomic force microscopy to assess 24 human cadaver eyes and found that the stiffness of the anterior corneal stroma increased significantly after cross-linking [97]. Further studies are needed to assess how it may apply to clinical diagnostic criteria.

\section{Optical coherence elastography (OCE)}

OCE is able to assess localized mechanical stress on the cornea via a noncontact based system such as an air puff or a contact-based system such as anaesthetic drops, coupled with the use of OCT to track the corneal deformation $[98,99]$. Singh et al. describes the ability to separate phase velocities of the elastic wave in different layers of the cornea, and found that this method was able to detect a change in elasticity in porcine corneas after cross-linking [100]. Though studies are currently limited, this may serve to be an alternate technique to noninvasively and accurately assess local biomechanical corneal distortions.

\section{Conclusions}

The detection of subclinical keratoconus is challenging as there are no uniform diagnostic criteria. As shown by the response to the attempt by Gomes et al. to establish a global consensus, such a conclusion remains elusive [3]. Despite the availability of multiple imaging modalities, there is still controversy with regards to detecting subclinical keratoconus. When assessing patients prior to refractive surgery, being conscious of multiple modalities for diagnosing subclinical keratoconus can aid in improved diagnosis and reducing risk of post-refractive ectasia (Table 3). Furthermore, accurate early identification of keratoconus can allow for earlier cross-linking treatments and thus decrease future disease burden. Further studies are needed to better identify a universal set of criteria to identify subclinical keratoconus. Technologies such as polarization sensitivity OCT, atomic force microscopy, Brillouin light-scattering microscopy, and optical coherence elastography may be promising new modalities that can be adapted into clinical practice.

\section{Compliance with ethical standards}

Conflict of interest The authors declare that they have no conflict of interest.

Publisher's note Springer Nature remains neutral with regard to jurisdictional claims in published maps and institutional affiliations.

\section{References}

1. Vazirani J, Basu S. Keratoconus: current perspectives. Clin Ophthalmol. 2013;7:2019-30. https://doi.org/10.2147/OPTH. S50119.

2. Rabinowitz YS. Keratoconus. Surv Ophthalmol. 1998;42: 297-319.

3. Gomes JA, Tan D, Rapuano C, Belin MW, Ambrósio R, José G, et al. Global consensus on keratoconus and ectatic diseases. Cornea. 2015;34:359-69. https://doi.org/10.1097/ICO.0000000000000408.

4. Ambrósio R, Klyce SD, Wilson SE. Corneal topographic and pachymetric screening of keratorefractive patients. J Refract Surg. 2003;19:24-9.

5. Vinciguerra R, Romano MR, Camesasca FI, Azzolini C, Silvia $\mathrm{T}$, Morenghi E, et al. Corneal cross-linking as a treatment for keratoconus: four-year morphologic and clinical outcomes with respect to patient age. Ophthalmology. 2013;120:908-16. https:// doi.org/10.1016/j.ophtha.2012.10.023.

6. Tummanapalli SS, Potluri H, Vaddavalli PK, Sangwan VS. Efficacy of axial and tangential corneal topography maps in detecting subclinical keratoconus. J Cataract Refract Surg. 2015;41:2205-14. https://doi.org/10.1016/j.jcrs.2015.10.041.

7. McMahon TT, Szczotka-Flynn L, Barr JT, Anderson RJ, Slaughter ME, Lass JH, et al. A new method for grading the severity of keratoconus: the Keratoconus Severity Score (KSS). Cornea. 2006;25:794-800. https://doi.org/10.1097/01.ico. 0000226359.26678.d1.

8. Saad A, Gatinel D. Screening for keratoconus: lack of a scientific base regarding the global consensus? Cornea. 2015;34:e33-4. https://doi.org/10.1097/ICO.0000000000000620.

9. Randleman J, Dupps W, Santhiago M, Rabinowitz YS, Koch $\mathrm{DD}$, Stulting RD, et al. Screening for keratoconus and related ectatic corneal disorders. Cornea. 2015;34. https://doi.org/10. 1097/ICO.0000000000000500.

10. Godefrooij DA, Galvis V, Tello A. Von Helmholtz's ophthalmometer: historical review and experience with one of the last surviving original devices. Acta Ophthalmol. 2018;96:314-20. https://doi.org/10.1111/aos.13493.

11. Hashemi H, Yekta A, Khabazkhoob M. Effect of keratoconus grades on repeatability of keratometry readings: comparison of 5 devices. J Cataract Refract Surg. 2015;41:1065-72. https://doi. org/10.1016/j.jcrs.2014.08.043.

12. Wilson SE, Klyce SD. Screening for corneal topographic abnormalities before refractive surgery. Ophthalmology. 1994;101:147-52. https://doi.org/10.1016/S0161-6420(94)31372-8.

13. Martin R. Cornea and anterior eye assessment with placido-disc keratoscopy, slit scanning evaluation topography and scheimpflug imaging tomography. Indian J Ophthalmol. 2018;66:360-6. https://doi.org/10.4103/ijo.IJO_850_17.

14. Savini G, Barboni P, Carbonelli M, Hoffer KJ. Repeatability of automatic measurements by a new Scheimpflug camera combined with Placido topography. J Cataract Refract Surg. 2011;37:1809-16. https://doi.org/10.1016/j.jcrs.2011.04.033.

15. Piñero DP, Alió JL, Alesón A, Escaf Vergara M, Miranda M. Corneal volume, pachymetry, and correlation of anterior and posterior corneal shape in subclinical and different stages of clinical keratoconus. J Cataract Refract Surg. 2010;36:814-25. https://doi.org/10.1016/j.jcrs.2009.11.012.

16. Maeda N, Klyce SD, Smolek MK. Comparison of methods for detecting keratoconus using videokeratography. Arch Ophthalmol 1995;113:870-4. https://doi.org/10.1001/archopht.1995. 01100070044023 .

17. Naderan M, Jahanrad A, Farjadnia M. Ocular, corneal, and internal aberrations in eyes with keratoconus, forme fruste 
keratoconus, and healthy eyes. Int Ophthalmol 2018;38:1565-73. https://doi.org/10.1007/s10792-017-0620-5.

18. Smolek MK, Klyce SD. Current keratoconus detection methods compared with a neural network approach. Investig Ophthalmol Vis Sci. 1997;38:2290-9.

19. Maeda N, Klyce SD, Smolek MK, Thompson HW. Automated keratoconus screening with corneal topography analysis. Investig Ophthalmol Vis Sci. 1994;35:2749-57.

20. Sedghipour MR, Sadigh AL, Motlagh BF. Revisiting corneal topography for the diagnosis of keratoconus: use of Rabinowitz's KISA\% index. Clin Ophthalmol. 2012;6:181-4. https://doi.org/ 10.2147/OPTH.S24219.

21. Cavas-Martínez F, De la Cruz Sánchez E, Nieto Martínez J, Fernández Cañavate FJ, Fernández-Pacheco DG. Corneal topography in keratoconus: state of the art. Eye Vis. 2016;3:5. https:// doi.org/10.1186/s40662-016-0036-8.

22. Rabinowitz YS, Rasheed K. KISA\% index: a quantitative videokeratography algorithm embodying minimal topographic criteria for diagnosing keratoconus. J Cataract Refract Surg. 1999;25:1327-35. https://doi.org/10.1016/S0886-3350(99)00195-9.

23. Rabinowitz YS. Videokeratographic indices to aid in screening for keratoconus. J Refract Surg. 1995;11:371-9.

24. Maeda N, Klyce SD, Smolek MK. Neural network classification of corneal topography. Preliminary demonstration. Investig Ophthalmol Vis Sci. 1995;36:1327-35.

25. Wilson SE, Lin DT, Klyce SD, Reidy JJ, Insler MS. Topographic changes in contact lens-induced corneal warpage. Ophthalmology. 1990;97:734-44. https://doi.org/10.1016/s0161-6420(90) 32516-2.

26. Cerviño A, Hosking SL, Montés-Micó R. Comparison of higher order aberrations measured by NIDEK OPD-Scan dynamic skiascopy and Zeiss WASCA Hartmann-Shack aberrometers. J Refract Surg. 2008;24:790-6. https://doi.org/10.3928/1081597X20081001-04.

27. Hamdi IM, Hamdi MM. Quality of vision after deep anterior lamellar keratoplasty (fluid dissection) compared to penetrating keratoplasty for the treatment of keratoconus. J Ophthalmol. 2017;2017. https://doi.org/10.1155/2017/4507989.

28. d'Azy CB, Pereira B, Chiambaretta F, Dutheil F. Efficacy of different procedures of intra-corneal ring segment implantation in keratoconus: a systematic review and meta-analysis. Transl Vis Sci Technol. 2019;8. https://doi.org/10.1167/tvst.8.3.38.

29. Asgari S, Hashemi H, Jafarzadehpur E, Mohamadi A, Mehravaran S, Fotouhi A. Low light visual function after accelerated corneal cross-linking protocols: $18 \mathrm{~mW} / \mathrm{cm}^{2}$ vs. $9 \mathrm{~mW} / \mathrm{cm}^{2}$. Rom J Ophthalmol. 2018;62:270-6.

30. Asgari S, Hashemi H. OPD scan III accuracy: topographic and aberrometric indices after accelerated corneal cross-linking. J Curr Ophthalmol. 2017;30:58-62. https://doi.org/10.1016/j.joco. 2017.09.004.

31. Auffarth GU, Wang L, Völcker HE. Keratoconus evaluation using the Orbscan topography system. J Cataract Refract Surg. 2000;26:222-8. https://doi.org/10.1016/S0886-3350(99)00355-7.

32. Steele TM, Fabinyi DC, Couper TA, Loughnan MS. Prevalence of Orbscan II corneal abnormalities in relatives of patients with keratoconus. Clin Exp Ophthalmol. 2008;36:824-30. https://doi. org/10.1111/j.1442-9071.2009.01908.x.

33. Rao SN, Raviv T, Majmudar PA, Epstein RJ. Role of Orbscan II in screening keratoconus suspects before refractive corneal surgery. Ophthalmology. 2002;109:1642-6. https://doi.org/10. 1016/S0161-6420(02)01121-1.

34. Gharieb HM, Othman IS, Elkitkat RS. Orbscan 3 versus Pentacam HR: evaluating the possible interchangeable use of various parameters. Cornea. 2020. https://doi.org/10.1097/ICO. 0000000000002257. Published online January 27.
35. Medghalchi A, Moghadam RS, Akbari M, et al. Correlation of corneal elevations measured by Scheimpflug corneal imaging with severity of keratoconus. J Curr Ophthalmol. 2019;31: 377-81. https://doi.org/10.1016/j.joco.2019.06.007.

36. Duncan JK, Belin MW, Borgstrom M. Assessing progression of keratoconus: novel tomographic determinants. Eye Vis. 2016;3. https://doi.org/10.1186/s40662-016-0038-6.

37. Belin MW, Duncan JK. Keratoconus: the ABCD grading system. Klin Monatsbl Augenheilkd. 2016;233:701-7. https://doi.org/10. 1055/s-0042-100626.

38. Lopes BT, Ramos IC, Dawson DG, Belin MW, Ambrósio R. Detection of ectatic corneal diseases based on pentacam. Z Für Med Phys. 2016;26:136-42. https://doi.org/10.1016/j.zemedi. 2015.11.001.

39. Sedaghat M-R, Momeni-Moghaddam H, Belin M, et al. Changes in the $\mathrm{ABCD}$ keratoconus grade after intracorneal ring segment implantation. Cornea 2018;37:1431-7. https://doi.org/10.1097/ ICO.0000000000001648.

40. Cui J, Zhang X, Hu Q, Zhou W-Y, Yang F. Evaluation of corneal thickness and volume parameters of subclinical keratoconus using a Pentacam Scheimflug system. Curr Eye Res. 2016;41:923-6. https://doi.org/10.3109/02713683.2015.1082188.

41. Shen Y, Han T, Jhanji V, et al. Correlation between corneal topographic, densitometry, and biomechanical parameters in Keratoconus eyes. Transl Vis Sci Technol. 2019;8. https://doi. org/10.1167/tvst.8.3.12.

42. de Sanctis U, Loiacono C, Richiardi L, Turco D, Mutani B, Grignolo FM. Sensitivity and specificity of posterior corneal elevation measured by Pentacam in discriminating keratoconus/ subclinical keratoconus. Ophthalmology. 2008;115:1534-9. https://doi.org/10.1016/j.ophtha.2008.02.020.

43. Miháltz K, Kovács I, Takács A, Nagy ZZ. Evaluation of keratometric, pachymetric, and elevation parameters of keratoconic corneas with pentacam. Cornea. 2009;28:976-80. https://doi.org/ 10.1097/ICO.0b013e31819e34de.

44. Muftuoglu O, Ayar O, Ozulken K, Ozyol E, Akıncı A. Posterior corneal elevation and back difference corneal elevation in diagnosing forme fruste keratoconus in the fellow eyes of unilateral keratoconus patients. J Cataract Refract Surg. 2013;39:1348-57. https://doi.org/10.1016/j.jcrs.2013.03.023.

45. McAlinden C, Schwiegerling J, Khadka J, Pesudovs K. Corneal aberrations measured with the Oculus Pentacam HR: repeatability and reproducibility. J Cataract Refract Surg. 2020. https:// doi.org/10.1097/j.jcrs.0000000000000084. Published online February 6.

46. Pereira JMM, Neves A, Alfaiate P, Santos M, Aragão H, Sousa JC. Lenstar ${ }^{\circledR}$ LS 900 vs. Pentacam ${ }^{\circledR}$-AXL: comparative study of ocular biometric measurements and intraocular lens power calculation. Eur J Ophthalmol. 2018;28:645-51. https://doi.org/10. 1177/1120672118771844.

47. Zhang Y, Chen YG, Yang HY, Xia YJ, Zhao R. Analysis on the role of Sirius combined topography and tomography system in screening for suspect keratoconus. Zhonghua Yan Ke Za Zhi Chin J Ophthalmol. 2018;54:33-8. https://doi.org/10.3760/cma.j. issn.0412-4081.2018.01.007.

48. Arbelaez MC, Versaci F, Vestri G, Barboni P, Savini G. Use of a support vector machine for keratoconus and subclinical keratoconus detection by topographic and tomographic data. Ophthalmology. 2012;119:2231-8. https://doi.org/10.1016/j.ophtha.2012.06.005.

49. Ladi JS, Shah NA. Comparison of central corneal thickness measurements with the Galilei dual Scheimpflug analyzer and ultrasound pachymetry. Indian J Ophthalmol. 2010;58:385-8. https://doi.org/10.4103/0301-4738.67045.

50. Moshirfar M, Motlagh MN, Murri MS, Momeni-Moghaddam H, Ronquillo YC, Hoopes PC. Galilei corneal tomography for 
screening of refractive surgery candidates: a review of the literature, part II. Med Hypothesis Discov Innov Ophthalmol. 2019;8:204-18.

51. Feizi S, Yaseri M, Kheiri B. Predictive ability of Galilei to distinguish subclinical keratoconus and keratoconus from normal corneas. J Ophthalmic Vis Res. 2016;11:8-16. https://doi.org/10. 4103/2008-322X.180707.

52. Jafarinasab MR, Feizi S, Karimian F, Hasanpour H. Evaluation of corneal elevation in eyes with subclinical keratoconus and keratoconus using Galilei double Scheimpflug analyzer. Eur J Ophthalmol. 2013;23:377-84. https://doi.org/10.5301/ejo.5000226.

53. Shetty R, Arora V, Jayadev C, et al. Repeatability and agreement of three Scheimpflug-based imaging systems for measuring anterior segment parameters in keratoconus. Investig Ophthalmol Vis Sci. 2014;55:5263-8. https://doi.org/10.1167/iovs.14-15055.

54. Meyer JJ, Gokul A, Vellara HR, Prime Z, McGhee CNJ. Repeatability and agreement of Orbscan II, Pentacam HR, and Galilei tomography systems in corneas with keratoconus. Am J Ophthalmol. 2017;175:122-8. https://doi.org/10.1016/j.ajo.2016. 12.003 .

55. Karnowski K, Kaluzny BJ, Szkulmowski M, Gora M, Wojtkowski M. Corneal topography with high-speed swept source OCT in clinical examination. Biomed Opt Express. 2011;2: 2709-20. https://doi.org/10.1364/BOE.2.002709.

56. Yip H, Chan E. Optical coherence tomography imaging in keratoconus. Clin Exp Optom. 2019;102:218-23. https://doi.org/10. $1111 /$ cxo. 12874.

57. Schröder S, Mäurer S, Eppig T, Seitz B, Rubly K, Langenbucher A. Comparison of corneal tomography: repeatability, precision, misalignment, mean elevation, and mean pachymetry. Curr Eye Res. 2018;43:709-16. https://doi.org/10.1080/02713683.2018. 1441873.

58. Wang C, Xia X, Tian B, Zhou S. Comparison of Fourier-domain and Time-domain optical coherence tomography in the measurement of thinnest corneal thickness in keratoconus. J Ophthalmol. 2015;2015. https://doi.org/10.1155/2015/402925.

59. Ramos J, Li Y, Huang D. Clinical and research applications of anterior segment optical coherence tomography-a review. Clin Exp Ophthalmol. 2008;37:81-9. https://doi.org/10.1111/j.14429071.2008.01823.x.

60. Li Y, Meisler DM, Tang M, Lu AT, Thakrar V, Reiser BJ, et al. Keratoconus diagnosis with optical coherence tomography pachymetry mapping. Ophthalmology. 2008;115:2159-66. https://doi.org/10.1016/j.ophtha.2008.08.004.

61. Qin B, Chen S, Brass R, Li Y, Tang M, Zhang X, et al. Keratoconus diagnosis with an optical coherence tomography-based pachymetric scoring system. J Cataract Refract Surg. 2013;39:1864-71.

62. Steinberg J, Casagrande M, Frings A, Katz T, Druchkiv V, Richard G, et al. Screening for subclinical keratoconus using swept-source Fourier domain anterior segment optical coherence tomography. Cornea. 2015;34:1413-9. https://doi.org/10.1097/ ICO.0000000000000568.

63. Chan TCY, Biswas S, Yu M, Jhanji V. Comparison of corneal measurements in keratoconus using swept-source optical coherence tomography and combined Placido-Scheimpflug imaging. Acta Ophthalmol. 2017;95:e486-94. https://doi.org/10.1111/aos. 13298.

64. Miller AR, Roisman L, Zhang Q, Zheng F, Dias J, Yehoshua Z, et al. Comparison between spectral-domain and swept-source optical coherence tomography angiographic imaging of choroidal neovascularization. Investig Ophthalmol Vis Sci. 2017;58:1499-505. https://doi.org/10.1167/iovs.16-20969.

65. Gutierrez-Bonet R, Ruiz-Medrano J, Biarnés M, Rasheed MA, Vupparaboina KK, Chhablani J, et al. Analysis of choroidal vascularity index in keratoconus patients using swept-source optical coherence tomography-based binarization techniques. J Ophthalmol. 2020;2020:1682463. https://doi.org/10.1155/2020/ 1682463.

66. Ghoreishi SM, Mortazavi SAA, Abtahi Z-A, Abtahi M-A, Sonbolestan SA, Abtahi S-H, et al. Comparison of Scheimpflug and swept-source anterior segment optical coherence tomography in normal and keratoconus eyes. Int Ophthalmol. 2017;37:965-71. https://doi.org/10.1007/s10792-016-0347-8.

67. Jhanji V, Yang B, Yu M, Ye C, Leung CKS. Corneal thickness and elevation measurements using swept-source optical coherence tomography and slit scanning topography in normal and keratoconic eyes. Clin Exp Ophthalmol. 2013;41:735-45. https:// doi.org/10.1111/ceo.12113.

68. Temstet C, Sandali O, Bouheraoua N, Hamiche T, Galan A, Sanharawi ME, et al. Corneal epithelial thickness mapping using Fourier-domain optical coherence tomography for detection of form fruste keratoconus. J Cataract Refract Surg. 2015;41:812-20. https://doi.org/10.1016/j.jcrs.2014.06.043.

69. OSTADIAN F, FARRAHI F, MAHDIAN RADA. Comparison of corneal epithelial thickness map measured by spectral domain optical coherence tomography in healthy, subclinical and early keratoconus subjects. Med Hypothesis Discov Innov Ophthalmol. 2019;8:85-91.

70. Li Y, Tan O, Brass R, Weiss JL, Huang D. Corneal epithelial thickness mapping by Fourier-domain optical coherence tomography in normal and keratoconic eyes. Ophthalmology. 2012;119:2425-33. https://doi.org/10.1016/j.ophtha.2012.06. 023.

71. Rocha KM, Straziota CP, Stulting RD, Randleman JB, SpectralDomain OCT. Analysis of regional epithelial thickness profiles in keratoconus, postoperative corneal ectasia, and normal eyes. J Refract Surg. 2013;29:173-9. https://doi.org/10.3928/1081597X20130129-08.

72. Götzinger E, Pircher M, Dejaco-Ruhswurm I, Kaminski S, Skorpik C, Hitzenberger CK. Imaging of birefringent properties of keratoconus corneas by polarization-sensitive optical coherence tomography. Investig Ophthalmol Vis Sci. 2007;48:3551-8. https://doi.org/10.1167/iovs.06-0727.

73. Daxer A, Fratzl P. Collagen fibril orientation in the human corneal stroma and its implication in keratoconus. Investig Ophthalmol Vis Sci. 1997;38:121-9.

74. Meek KM, Tuft SJ, Huang Y, et al. Changes in collagen orientation and distribution in keratoconus corneas. Investig Ophthalmol Vis Sci. 2005;46:1948-56. https://doi.org/10.1167/ iovs.04-1253.

75. Götzinger E, Pircher M, Sticker M, Fercher AF, Hitzenberger CK. Measurement and imaging of birefringent properties of the human cornea with phase-resolved, polarization-sensitive optical coherence tomography. J Biomed Opt. 2004;9:94-102. https:// doi.org/10.1117/1.1629308.

76. Fukuda S, Yamanari M, Lim Y, et al. Keratoconus diagnosis using anterior segment polarization-sensitive optical coherence tomography. Investig Ophthalmol Vis Sci. 2013;54:1384-91. https://doi.org/10.1167/iovs.12-10979.

77. Ozgurhan EB, Kara N, Yildirim A, Bozkurt E, Uslu H, Demirok A. Evaluation of corneal microstructure in keratoconus: a confocal microscopy study. Am J Ophthalmol. 2013;156:885-93.e2. https://doi.org/10.1016/j.ajo.2013.05.043.

78. Weed KH, MacEwen CJ, Cox A, McGhee CNJ. Quantitative analysis of corneal microstructure in keratoconus utilising in vivo confocal microscopy. Eye. 2007;21:614-23. https://doi. org/10.1038/sj.eye.6702286.

79. Erie JC, Patel SV, McLaren JW, Nau CB, Hodge DO, Bourne WM. Keratocyte density in keratoconus. A confocal microscopy study(a). Am J Ophthalmol. 2002;134:689-95. https://doi.org/ 10.1016/s0002-9394(02)01698-7. 
80. Uçakhan OO, Kanpolat A, Ylmaz N, Ozkan M. In vivo confocal microscopy findings in keratoconus. Eye Contact Lens 2006;32:183-91. https://doi.org/10.1097/01.icl.0000189038. 74139.4a.

81. Roberts CJ, Dupps WJ. Biomechanics of corneal ectasia and biomechanical treatments. J Cataract Refract Surg. 2014;40:991-8. https://doi.org/10.1016/j.jcrs.2014.04.013.

82. Vinciguerra R, Ambrósio R, Roberts CJ, Azzolini C, Vinciguerra P. Biomechanical characterization of subclinical keratoconus without topographic or tomographic abnormalities. J Refract Surg. 2017;33:399-407. https://doi.org/10.3928/1081597X-20170213-01.

83. Terai N, Raiskup F, Haustein M, Pillunat LE, Spoerl E. Identification of biomechanical properties of the cornea: the ocular response analyzer. Curr Eye Res. 2012;37:553-62. https://doi. org/10.3109/02713683.2012.669007.

84. Mikielewicz M, Kotliar K, Barraquer RI, Michael R. Air-pulse corneal applanation signal curve parameters for the characterisation of keratoconus. Br J Ophthalmol. 2011;95:793-8. https:// doi.org/10.1136/bjo.2010.188300.

85. Galletti JD, Ruiseñor Vázquez PR, Fuentes Bonthoux F, Pförtner T, Galletti JG. Multivariate analysis of the ocular response analyzer's corneal deformation response curve for early keratoconus detection. J Ophthalmol. https://doi.org/10.1155/2015/ 496382.

86. Schweitzer C, Roberts CJ, Mahmoud AM, Colin J, MauriceTison S, Kerautret J. Screening of forme fruste keratoconus with the ocular response analyzer. Invest Ophthalmol Vis Sci. 2010;51:2403-10. https://doi.org/10.1167/iovs.09-3689.

87. Ambrósio R Jr, Ramos I, Luz A, et al. Dynamic ultra high speed Scheimpflug imaging for assessing corneal biomechanical properties. Rev Bras Oftalmol 2013;72:99-102. https://doi.org/ 10.1590/S0034-72802013000200005.

88. Vinciguerra R, Ambrósio R, Elsheikh A, et al. Detection of keratoconus with a new biomechanical index. J Refract Surg. 2016;32:803-10. https://doi.org/10.3928/1081597X-2016062901.

89. Hosseini SM. Comparison among ocular response analyzer, Corvis ST and Goldmann applanation tonometry in healthy children. Int J Ophthalmol. 2018;11:1330-6. https://doi.org/10. 18240/ijo.2018.08.13.

90. Wu Y, Li XL, Yang SL, Yan XM, Li HL. Examination and discriminant analysis of corneal biomechanics with CorVis ST in keratoconus and subclinical keratoconus. Beijing Da Xue Xue Bao. 2019;51:881-6.

91. Kataria P, Padmanabhan P, Gopalakrishnan A, Padmanaban V, Mahadik S, Ambrósio R. Accuracy of Scheimpflug-derived corneal biomechanical and tomographic indices for detecting subclinical and mild keratectasia in a South Asian population. J Cataract Refract Surg. 2019;45:328-36. https://doi.org/10.1016/ j.jcrs.2018.10.030.

92. Scarcelli G, Besner S, Pineda R, Yun SH. Biomechanical characterization of keratoconus corneas ex vivo with Brillouin microscopy. Investig Ophthalmol Vis Sci. 2014;55:4490-5. https://doi.org/10.1167/iovs.14-14450.

93. Shao P, Eltony AM, Seiler TG, Tavakol B, Pineda R, Koller T, et al. Spatially-resolved Brillouin spectroscopy reveals biomechanical abnormalities in mild to advanced keratoconus in vivo. Sci Rep. 2019;9. https://doi.org/10.1038/s41598-019-43811-5.

94. Seiler TG, Shao P, Eltony A, Seiler T, Yun S-H. Brillouin spectroscopy of normal and keratoconus corneas. Am J Ophthalmol. 2019;202:118-25. https://doi.org/10.1016/j.ajo.2019. 02.010 .

95. Webb JN, Langille E, Hafezi F, Randleman JB, Scarcelli G. Biomechanical impact of localized corneal cross-linking beyond the irradiated treatment area. J Refract Surg. 2019;35:253-60. https://doi.org/10.3928/1081597X-20190304-01.

96. Hammer CM, Schäffer TE. Atomic force microscopy crosslinks interdisciplinary eye research. Med Hypothesis Discov Innov Ophthalmol. 2015;4:1-4.

97. Dias J, Diakonis VF, Kankariya VP, Yoo SH, Ziebarth NM. Anterior and posterior corneal stroma elasticity after corneal collagen crosslinking treatment. Exp Eye Res. 2013;116:58-62. https://doi.org/10.1016/j.exer.2013.07.028.

98. Kirby MA, Pelivanov I, Song S, Ambrozinski, Yoon SJ, Gao L, et al. Optical coherence elastography in ophthalmology. J Biomed Opt. 2017;22. https://doi.org/10.1117/1.JBO.22.12.121720.

99. Schmitt J. OCT elastography: imaging microscopic deformation and strain of tissue. Opt Express. 1998;3:199-211. https://doi. org/10.1364/oe.3.000199.

100. Singh M, Li J, Vantipalli S, et al. Noncontact elastic wave imaging optical coherence elastography for evaluating changes in corneal elasticity due to crosslinking. IEEE J Sel Top Quantum Electron. 2016;22. https://doi.org/10.1109/JSTQE.2015. 2510293. 